\title{
Nursing Care and Patient Safety: Visualizing Medication Organization, Storage and Distribution with Photographic Research Methods ${ }^{1}$
}

\author{
Anna Carolina Raduenz ${ }^{2}$ \\ Priscila Hoffmann ${ }^{2}$ \\ Vera Radunz ${ }^{3}$ \\ Grace Teresinha Marcon Dal Sasso ${ }^{4}$ \\ Isabel Cristina Alves Maliska ${ }^{5}$ \\ Patricia Beryl Marck ${ }^{6}$
}

In this qualitative study, we adapted photographic research methods from earlier nursing research to identify factors related to organization, storage and distribution that could lead to errors in the selection, preparation and administration of medications. The research excerpt presented here was developed in a clinical unit of an urban Brazilian public hospital. The research participants were nurses working at that unit and students from the two final semesters of the Undergraduate Nursing Course. We collected digital photographs of the medication system and subsequently used photo elicitation to review the images with research participants, so as to obtain their perceptions and narratives of working with medications in the unit. We report selected findings here on the organization, storage and distribution of medications, which indicate there is room to improve the safety of the medication system.

Descriptors: Safety Management; Medication Systems; Nursing Care; Photography; Qualitative Research.

\footnotetext{
${ }^{1}$ This research was supported by the University of Alberta Fund for Support of International Development Activities, Canada.

2 RN, Secretaria Municipal de Saúde, SC, Brazil. Comforting \& Caring Research Group, Universidade Federal de Santa Catarina, SC, Brazil. E-mail: Anna Carolina - katuka_carol@hotmail.com, Priscila - priscilahoffmann@hotmail.com.

${ }^{3}$ RN, Ph.D. in Nursing, Associate Professor, Departamento de Enfermagem, Centro de Ciências da Saúde, Universidade Federal de Santa Catarina, SC, Brazil. Comforting \& Caring Research Group, Universidade Federal de Santa Catarina, SC, Brazil. E-mail: radunz@ccs.ufsc.br.

${ }^{4}$ RN, Ph.D. in Health Informatics, Associate Professor, Departamento de Enfermagem, Centro de Ciências da Saúde, Universidade Federal de Santa Catarina, SC, Brazil. Technology, Information and Health Informatics and Nursing Research Group, Universidade Federal de Santa Catarina, SC, Brazil. E-mail: grace@matrix.com.br.

${ }^{5}$ RN, M.Sc. in Nursing, Hospital Universitário, Universidade Federal de Santa Catarina, SC, Brazil. Nursing Knowledge History Study Group, Universidade Federal de Santa Catarina, SC, Brazil. E-mail: isabel.alves07@yahoo.com.br.

${ }^{6}$ RN, Ph.D., Associate Professor, Faculty of Nursing, University of Alberta, Edmonton, Alberta, Canada. E-mail: patricia.marck@ualberta.ca.
}

Corresponding Author:

Patricia Beryl Marck

University of Alberta

6-10 University Terrace, 8303-112St Edmonton, AB Canada T6G 2T4.

E-mail: patricia.marck@ualberta.ca 


\section{Cuidados de enfermagem e segurança do paciente: visualizando a organização, acondicionamento e distribuição de medicamentos com método de pesquisa fotográfica}

Neste estudo qualitativo, adaptou-se o método de pesquisa fotográfica de estudos anteriores, para identificar fatores relacionados à organização, acondicionamento e distribuição que poderiam levar a erros na seleção, preparo e administração de medicamentos. O recorte da pesquisa apresentado foi desenvolvido em unidade de clínica médica de um hospital público, Brasil. Os participantes da pesquisa foram enfermeiros que trabalhavam naquela unidade e acadêmicos dos dois últimos semestres do curso de graduação em Enfermagem. Obtiveram-se fotografias digitais do sistema de medicação e, subsequentemente, utilizou-se a elicitação das fotos para rever imagens com os participantes da pesquisa, a fim de obter suas percepções e narrativas a respeito do trabalho com medicamentos, naquela unidade. Apresenta-se uma seleção dos principais achados da pesquisa sobre organização, acondicionamento e distribuição de medicamentos, indicando que há espaço para melhorar a segurança do sistema de medicação.

Descritores: Gerenciamento de Segurança; Sistemas de Medicação; Cuidados de Enfermagem; Fotografia; Pesquisa Qualitativa.

\section{Cuidado de enfermería y seguridad del paciente: visualizando la organización, acondicionamiento y distribución de medicamentos con método de investigación fotográfica}

En este estudio cualitativo, se adoptó el método de investigación fotográfica de estudios anteriores, para identificar factores relacionados a la organización, acondicionamiento y distribución, los que podrían conducir a errores en la selección, preparación y administración de medicamentos. Esta parte de la investigación que se presenta fue desarrollada en una unidad de clínica médica de un Hospital Público, en Brasil. Los participantes de la investigación fueron enfermeros que trabajaban en aquella unidad y estudiantes de los dos últimos semestres del Curso de Graduación en Enfermería. Fueron obtenidas fotografías digitales del sistema de medicación y subsecuentemente, se obtuvieron las fotos para analizar las imágenes con los participantes de la investigación, a fin de obtener sus percepciones y narrativas al respecto del trabajo con medicamentos en aquella unidad. Se presenta una selección de los principales hallazgos de la investigación sobre organización, acondicionamiento y distribución de medicamentos, indicando que hay espacio para mejorar la seguridad del sistema de medicación.

Descriptores: Administración de la Seguridad; Sistemas de Medicación; Atención de Enfermería; Fotografia; Investigación Cualitativa.

\section{Introduction}

Progress in health care research contributes to improvements in the delivery of care. Even with ongoing improvements to health systems, however, people are still subject to several risks when they receive care, particularly inside hospital environments. Accordingly, patient safety has become a central concern for health systems around the world since the 90's. Data obtained from the USA in 1999 indicate that health care errors cause between 44 and 98 thousand adverse events every year in the hospitals of that country ${ }^{(1)}$. Since this 
early work, a global movement in patient safety has gathered momentum.

In 2004, the World Health Organization (WHO) created the World Alliance project for Patient Safety, whose fundamental goal is to prevent harm to patients. One of the central elements of WHO's World Alliance is the action called "Global Challenge", which releases a priority subject every two years for adoption by WHO members. Previous foci for the Global Challenge initiative included hospital-acquired infections and the safety of surgery ${ }^{(2)}$. The ANVISA - National Health Surveillance Agency, which corresponds to the FDA in Brazil, prepared a national proposal for patient safety in 2007, designed to fit the WHO project. The aim is to identify the specific types and nature of safety problems in health services. ANVISA authorities realized the need for Brazilian participation, not only because of the great number of health services in the country, but also because of priority actions that have been undertaken to improve population health(3). The ANVISA proposal for patient safety aims to improve quality in hospital service. In October 2007, the ANVISA, in a partnership with the Health Ministry and Pan-American Health Organization (PAHO), promoted a workshop "Patient Safety: A Global Challenge", which raised debates and suggestions about addressing issues around the subject. On this occasion, one of the issues discussed was the safe administration of injectable medications ${ }^{(3)}$.

Institutions and organizations nationally and internationally have discussed medication safety. For example, the Joint Commission International Center for Patient Safety, a commission for hospital accreditation recognized as the leader in patient safety, set a $2008 \mathrm{goal}$ to improve the safety of high risk medications ${ }^{(4)}$. Also, in December 2007, the WHO World Alliance for Patient Safety in partnership with Canada, Germany, the Netherlands, New Zealand, the United Kingdom and the USA, defined five common problems in patient care and proposed solutions through operational protocols based on scientific evidence. These include the prevention of medication errors ${ }^{(5)}$. Assuring the safety of all who receive health services is one of the most important challenges healthcare faces today ${ }^{(6)}$. The identification, analysis and management of risks related to safety incidents are necessary to achieve safer patient care and minimize harm ${ }^{(7)}$. It is therefore clear that nurses' actions may contribute to prevent and avoid mistakes. Since Nursing has care as its essence ${ }^{(8)}$, nurses must advocate for health and nursing policy which ensures access to quality treatment, including the safe administration of medications.
The Code of Ethics for Nurses takes into consideration the population's need and right to nursing care, which is focused on the person, family and collective, and assumes that nurses along with patients advocate for health care that is free of preventable risks and harm and accessible to the whole population ${ }^{(9)}$. Improving safety in health care reduces the incidence of disease and harm, shortens the treatment and/or hospitalization time, improves or maintains the patient's functional status, and increases his or her sensation of well being ${ }^{(10-11)}$. However, even with the initiatives of institutions and world representatives, there is inadequate evidence on the best way to achieve medication safety in complex health systems.

In the hospital context, many factors can lead to harm for the patient. The client's environment embodies many physical, psychological, cultural and other factors that influence or affect well being and survival(10). Since nursing professionals are responsible for planning and properly intervening in order to maintain a safe environment, the development of nursing research on medication safety is vital. In this research excerpt, we report selected findings from reports of nurses and nursing professors about the organization, distribution and packaging of the medications in a Medical Clinic unit of an urban public teaching hospital in Brazil, factors that can lead to subsequent mistakes in the selection, preparation and administration of medications.

\section{Methodology and Methods}

This research was developed for the Nursing Undergraduate Course Conclusion Work of a federal university in Brazil with the collaboration of a Canadian university (see Support). The study was carried out in a Medical Clinic unit of an urban public teaching hospital. The location was chosen because it has a great number of patients with chronic diseases who frequently require a range of medications in their treatment over long periods of time. The study participants were nurses working in the Medical Clinic unit and students of the Nursing Undergraduate Course in the last periods who were willing to participate in this study. There were seventeen (17) research participants at the location, including 7 nurses and 10 students of the $7^{\text {th }}$ and $8^{\text {th }}$ grade of the Nursing Undergraduate Course.

Our research was guided by principles of sound qualitative research(12-13). Our methodological approach was specifically guided by previous studies and current projects where researchers have adapted photographic 
research methods from the field of ecological restoration, which is the study and repair of damaged ecosystems ${ }^{(14)}$ to study medication safety(15-17). In the restorative approach to photographic research, scientists work with local citizens to understand the conditions they live and work in as seen through the eyes of the community members ${ }^{(16-19)}$. The goals of restorative photography are not just to document everyday conditions, but also to understand how the culture and conditions of a place mutually shape each other. In its simplest sense, thinking restoratively as researchers means paying attention to how we treat each other and the places we share ${ }^{(16-20)}$. The restorative photographic methods that were adapted for use in our study include:

- digital photography walkabouts, where field photography is conducted to document medication safety practices and issues on the study unit ${ }^{(15-17)}$;

- photo elicitation, where images are reviewed with research participants to elicit their perceptions and narratives of working with medications at the unit(15-17);

- thematic analysis of the visual and interview data to create photo narratives of medication safety that represent typical practices, experiences, and issues with medications on the unit ${ }^{(15-17)}$.

The determinations of Resolution number 196/96 by the Health National Council, which concern ethical aspects of research with human beings, were fulfilled in the conduct of this project. In addition, formal consent was obtained from the research institution and approval from the Institutional Review Board of the Federal University of Santa Catarina, under number 177/2008. All nurses and students in this study were over 18 years old and legally qualified to participate, and all participants reviewed and signed the Informed Consent term. Ethical provisions were made throughout the study to protect the relationships between researchers and participants and to preserve the confidentiality and anonymity of participating nurses and students.

Data collection occurred in two phases. In Phase 1, members of the research team conducted a photographic walkabout to collect digital photographs of the organization, storage and distribution of medications in the nursing station and bandaging room of the Medical Clinic unit. The nursing station is the place where the medication preparation takes place and where most of the medications are stored. In this area, there were cabinets, drawers, counters and a refrigerator. In the bandaging room, only the emergency trolley held medications. In these two environments, not one staff member is responsible for the medication organization; there is only a chart where, every other day, a shift is expected to check the emergency trolley.

The collection of photographs took place on three days over a two-week timeframe, in the morning and afternoon periods. To ensure that we captured the medication system in its routine conditions, no employees were told about the photo walkabouts beforehand, and the photos were collected while there were no employees present in the locations. The researchers were careful not to change anything in the medication location, only the drawers and doors of the cabinets and the refrigerator were opened in order to get a better visualization of what they were storing.

The digital photographs were downloaded onto a computer and saved in a password protected media file. Ten (10) photographs were then selected by the research team to review with study participants in Phase 2 photo elicitation interviews. In Phase 2, data collection proceeded with participants in groups of 5 or less, as follows. First, the general aim of the research and a dictionary of medication safety terms were reviewed with participants to ensure common understandings of medication safety. This dictionary included definitions of: Adverse Medication Event; Adverse Medication Reaction; Critical Incident; Error; Medication Error; Near Accident; Potential Adverse Medication Event; Preventable(16). Following this introductory discussion, participants were invited to review the photographs one at a time and complete a Digital Photography Scoring Tool (DPST) ${ }^{(15)}$ where they could write down any comments, concerns, and observations about medication safety in relation to each photograph. Participants were informed that they should feel free to note anything that seemed relevant to them, whether it applied to the storage, organization, hygiene or other aspects of medication preparation and administration at their unit. While each participant reviewed the photographs and completed the DPST, there was no communication between participants and/or with the researchers. On completing a review of all 10 images, participants had the option to provide written answers to two questions: "If I could do anything in order to improve any of these areas in relation to the medication safety, I would like to...." and "In case you have other concerns about the medication safety that were not represented on these photographs, please describe them".

After the written DPST data for each participant were transcribed into password protected Word for Windows files, each nurse's DPST was identified by the letter " $N$ " and a number from 1 to 7 , and each student's DPST by the letter " $\mathrm{S}$ " and a number from 1 to 10 . This distinction 
between nurse and student data enabled us to analyze each data set separately as well as compare the two sets for areas of convergence and divergence in terms of demonstrated knowledge, reported experiences, and emerging themes about medication safety. To analyze the photographic and DPST data, we implemented an analytic protocol developed in the earlier Canadian research(16-18). The analytic protocol incorporates initial, independent, individual thematic analyses of the visual and narrative data in several steps, followed by team member comparisons of their independent reviews to identify areas of convergence, divergence and emerging themes. Examples of preliminary themes that emerged at this point in the analysis include: the cleanliness and hygiene of the photographed area (for example, the presence or absence of dirt, humidity or other contamination sources); the organization (the degree of mess, room, order) of the photographed area, the distribution of medications (presence of medications in similar packages, different pharmacological forms); storage (adequate and correct place); ease of usage (efficiency, function reliability, easy access); potential sources for near accidents or medication errors in the photographed area; and/or any other aspects related to medication safety that could be considered relevant in the photographed area.

\section{Results}

We report here on an interim analysis of selected data for 4 photographs collected during the research; further analysis of the remaining images is currently underway. From a total of 10 photographs participants reviewed, our initial thematic analysis of the data sets in relation to 4 of the photographs is presented here and illustrated with specific participant comments, observations and concerns. The analysis discussed is in relation to photographs of the medication leftover drawer; the emergency trolley drawer; the collective use medication cabinet and the refrigerator door.

Figure 1 (below) illustrates a drawer inside a cabinet at the nursing station. The medications on the tray are leftovers of discharged patients' individual medications. Keeping discharged patients' medications on the unit is a workaround the nursing staff has developed to ensure they have sufficient supplies of frequently used medications at the unit at all times. Workarounds are deviations from or violations of explicit or implicit rules, regulations or policies which workers execute to accomplish their work $^{(21)}$. However, as the photo illustrates, despite the presence of containers for each kind of medication, they are frequently mixed together.

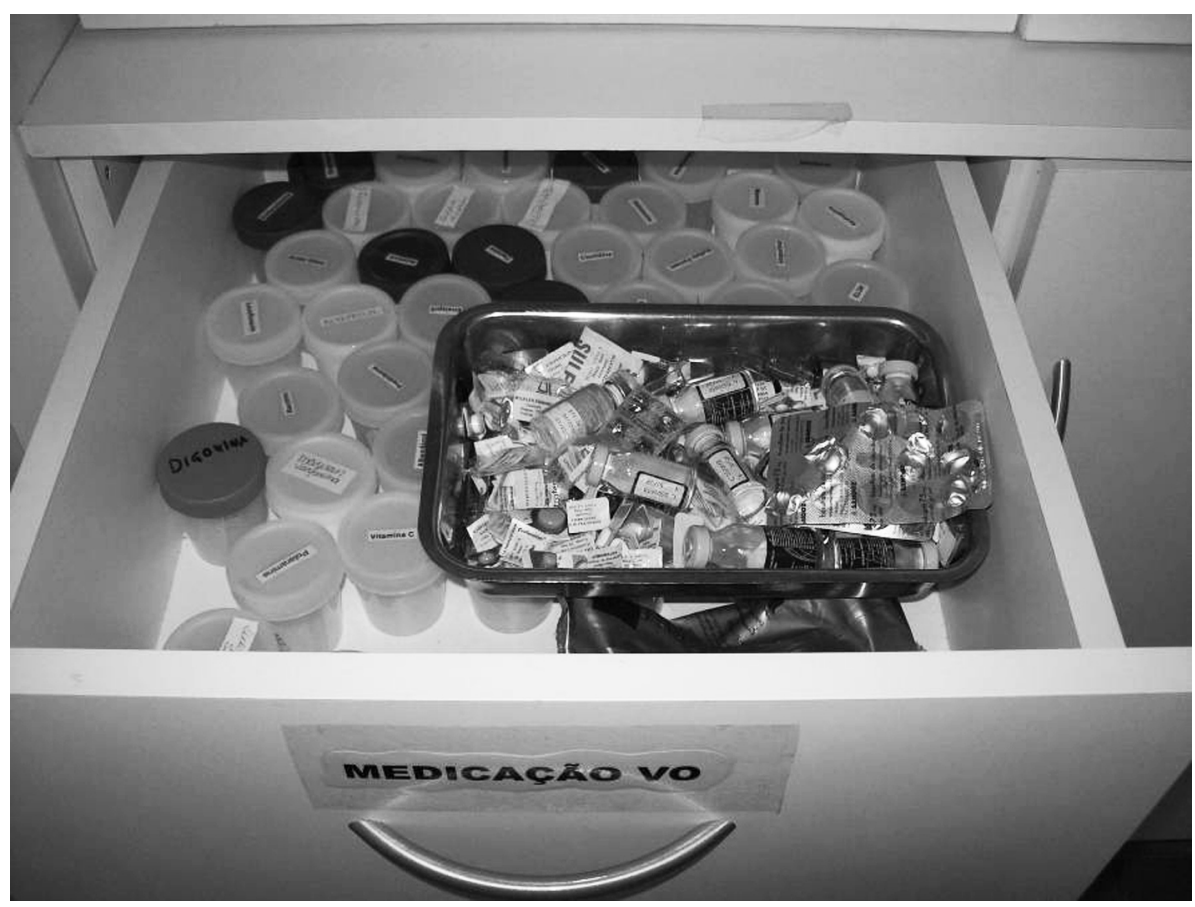

Figure 1 - Medication Leftover Drawer 
Nurse participants' comments on Figure 1 were diverse and reflected a range of observations about this photograph. As one noted: It needs organization and a better distribution for easier handling (N1). A second nurse observed: Some medications are already separated and identified, which as a consequence are searched for first. Many have a similar presentation (size, color, etc) and their identification comes on labels that can easily be taken off and changed. A lot of attention is needed when looking for a medication inside this drawer (N3). A third nurse's comments reflect similar concerns: Mixing of medications with different purposes and different administration routes. Medications that are very similar in their shapes and packages can possibly be swapped easily. The drawer identified as vo with medication for other administrations (N4).

Among student participants, comments about the mixing of medications and the wrong identification of the drawer were consistent. Some sample comments included: Drawer identification, presence of EV medications along with VO medications (S8); I think it is not safe enough, because the mixing of medications can lead to error, because they are presented as VO medications and also there are EV medications together (S9); and The orally taken medication writing is wrong, because there is EV medication together (S4). Notably, there were also comments on the safety of the medications stored separately, such as: Medications in the flasks ok! (S7) and The separated and named containers below are safer (S9).

Another aspect to be emphasized appeared in comments both nurses and students made, and related to the volume of medication leftovers. As one participant noted: Questions as to why so many leftovers? (S8), and as another stated: If the dose is individual, it is correct to return the medication leftovers to the pharmacy daily. It is necessary to store only the urgent medication with a pre-established quota in order to avoid exceeding the expiration date (S6).

Figure 1 illustrates the excess of medications on a tray, the mixing of various medications, the use of a drawer identified as "Oral Medication" to store medications for administration by other routes, and the presence of containers that are not being used to separate each medication. From the comments provided by participants, it is clear that neither the nurses nor the students view the current organization, storage and distribution system as optimally safe.

Figure 2 (below) captures an emergency trolley that is located in the procedure room in the admission area. It is located in a strategic place, easily accessible so that it can be transported to any location in case of an emergency inside the clinic. It is kept closed and covered to discourage staff from taking materials when these are lacking in other parts of the clinic.

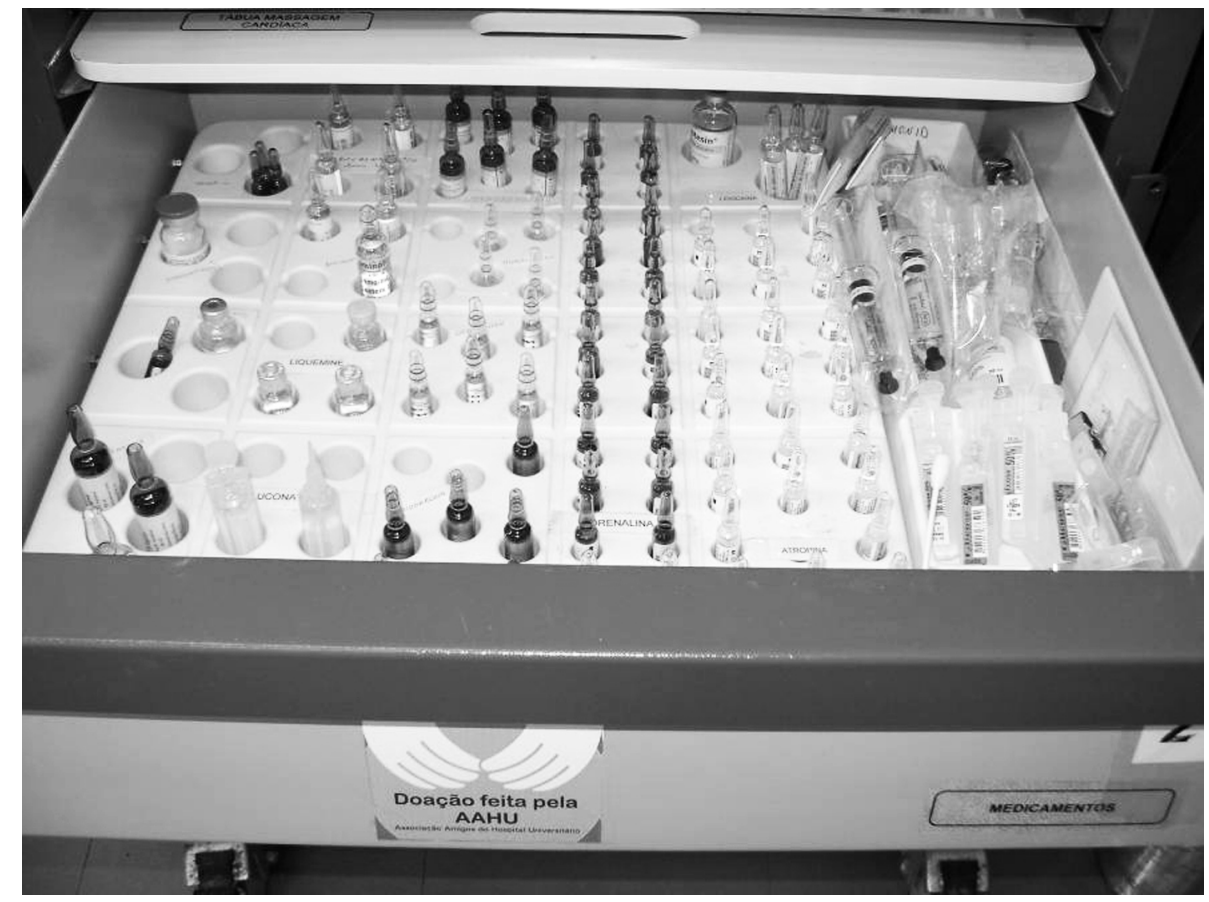

Figure 2 - Emergency trolley drawer 
Nurse participants offered varying comments about medication labeling and identification in relation to this image: Identified with safety (capital letters) and easily accessible (N2); Some medications on the tray have no identification (N4) and Most of the medications are identified, however some of them have no identification on the partitions, or the partitions are too large, and because of that, there can be more than one identification for the same medication (N7). Nurses also commented on the medications placed on the right side of the drawer: In this image we can observe the medications kept individually, except the ones on the right side, which for lack of room, are all piled up (N5) and It is difficult to find the medications in other partitions, because they are all piled up and left over (N7).

Student comments about the organization inside the drawer were decidedly mixed: Well distributed medications (S5); Medications organized in such a way that makes quick access and location easier (S6); Too messy on the right side
(S3); The right corner could be more organized (S7); The similar containers are too close to each other (S2) and [...] several similar packages, some of them at an inappropriate location (S10). Some students also observed the presence of empty spaces for the medications, such as: The trolley is not full; some of the medications are not there (S3) and Some empty spaces for the medications (S10).

Overall, participants' comments on Figure 2 reflected perceptions of adequate storage and distribution. However, their feedback suggests that some aspects of the organization of medications could be safer.

Figure 3 is of a cabinet with a medication stock for topical, injectable and oral application for all patients. It is used when there is the lack of individual patient medications, and other hospital units also borrow from this medication supply. This stock is replenished whenever there are few medications.

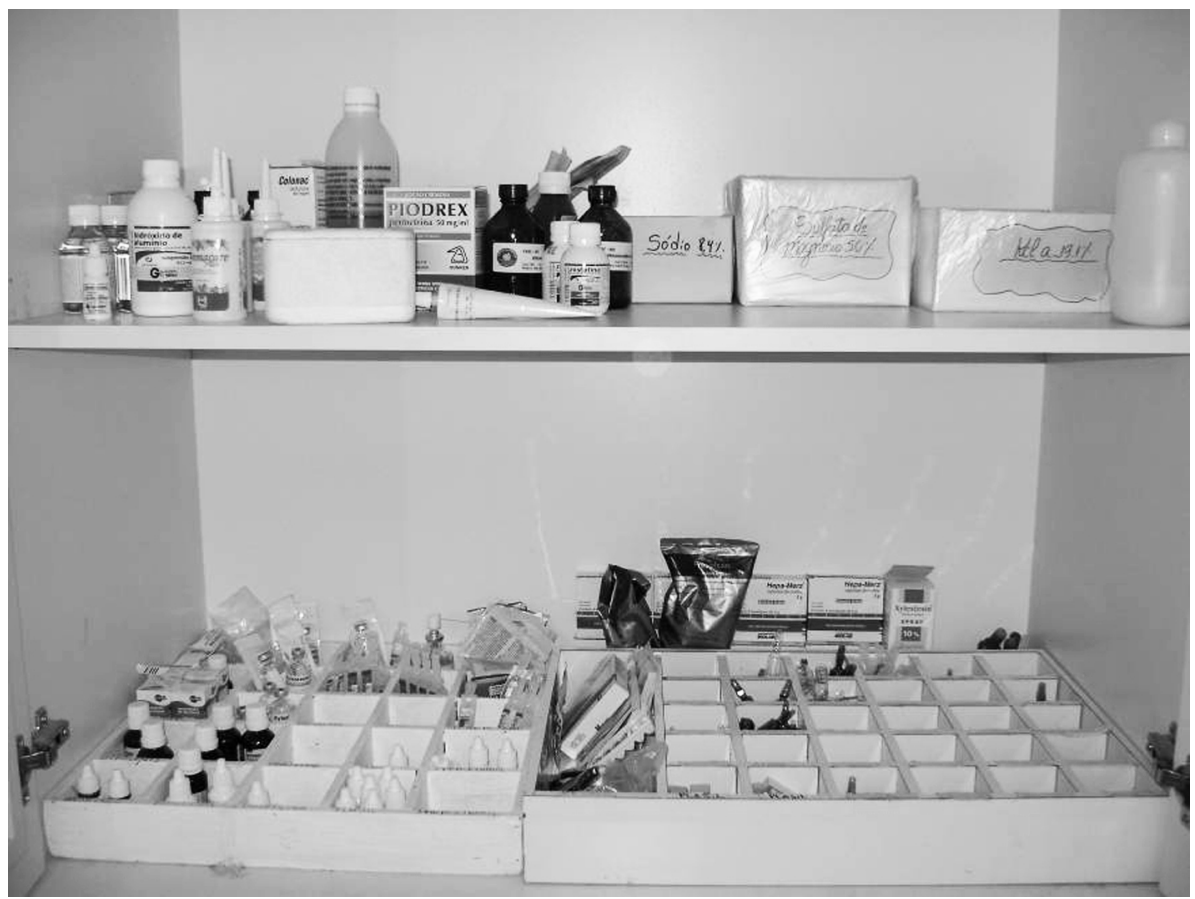

Figure 3 - Collective use medication cabinet

When reviewing Figure 3 with researchers, nurse participants emphasized the mixing of the medications and its risks: There are powders, ointments, creams, vials, solutions, causing disorganization and the risk of picking the wrong medication at the time of its use (N6) and Medications with different purposes, all mixed, making access to them difficult, increasing the risks (N7). Other participants commented on the excess of medications on the lower shelf: Although they are identified, it is very easy to wrongly pick one of the medications, especially when it overflows and the vials easily fall onto the other in/out tray (N2) and We were able to observe an excess of medications on the lower shelf and the bad use of the space (N5).

Among student participants, observations and comments included: Lack of organization, misplaced material (S1); Since it is a material stock, the medications could be better distributed (S9) and Many different things all mixed (S10). The students also noted issues with the storage of electrolytes, such as: Bandaging products too close to the electrolyte leftovers, and at the top of the medication shelf 
(S2) and The electrolytes could be better organized (S7). In addition, students also commented on the cleanliness of the station: Dirt on the boxes (S8) and The environment does not look quite clean and access for cleaning doesn't seem to be easy (S9).

Overall, nurses' and students' comments were quite similar when identifying issues with the organization and mixing of medications. The students referred to the hygiene of the environment and the need for better organization of the electrolytes, since their actions are quite different, and it is also easy to pick the wrong packages, as they are very similar.

The image in Figure 4 illustrates the storage of medications that need refrigeration. There is no separation of medications in the door or criteria for where to place each kind of medication. They are only stored according to the available shelves. Also, there is no rigorous control of the medication quantities.

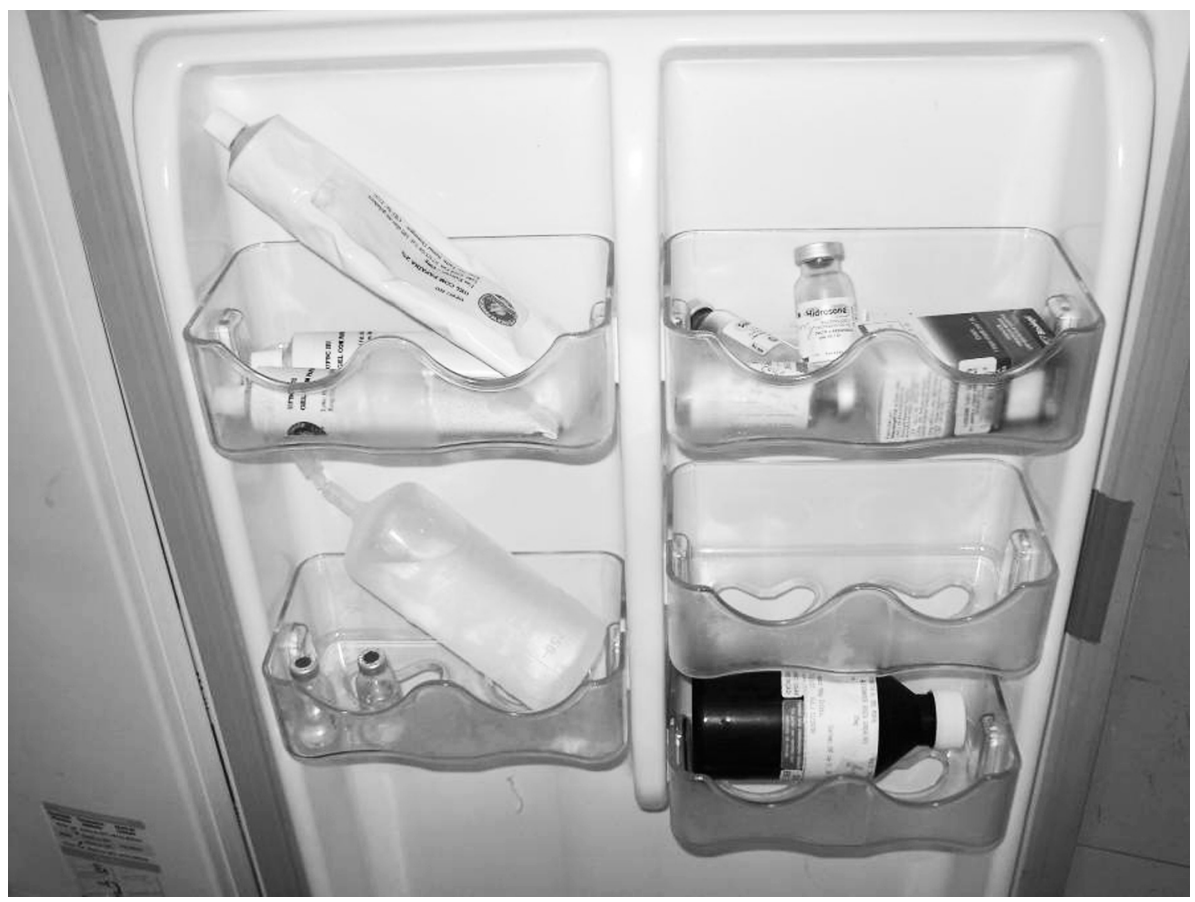

Figure 4 - Refrigerator door

The nurses emphasized three areas of concern in their comments: medication mixing, presence of open containers and temperature stability: [...] there are containers that were already opened without recording any identification of the expiration date (N2); Excess of mixed medications. Open containers without any identification (N3); Fridge door cannot adequately keep the temperature. Bad packaging, medications fallen on the ground and mixed... (N4) and Fridge door instantly loses temperature (...). It cannot hold insulin, chemotherapy drugs; there are new and used ointments together (risk of contamination for handling) [...] (N6).

Overall, both nurses and students noted multiple issues with the labeling, organization, storage and distribution of the medications in the refrigerator door. For example, student comments on Figure 4 included: Mixed medication. Inappropriate location (S4); Badly identified medications, badly distributed and running the risk of losing temperature (S5) and [...] they are apparently mixed [...]. This lack of organization leads to medication error (S9).
Research participants also frequently noted that, even though they worked everyday with medications under the conditions illustrated in the photographs, reviewing the images with researchers motivated them to pay attention to details they seldom noticed in their daily practice or internship routine. The consensus was that participating in photo elicitation not only enabled them to see their environment with different eyes; it also helped them to think over their practices and attitudes related to medication safety. This is consistent with the aim of restoration science in health care and in our world, which is to use research to think and act in ways that are more ecologically intelligent and, therefore, more ethically, scientifically and practically sound(16-20,22).

\section{Discussion}

Improving medication safety is a global goal because medication errors contribute significantly to the 
high rate of adverse events that occur every year within hospitals. Adverse medication events are frequently costly and harmful to patients, health care professionals and hospitals. Many initiatives focusing on medication safety have been launched around the world, but we still need more research to determine the most costeffective interventions to create safer systems and the safest possible patient care. The present study intends to raise the interest of hospital institutions, health centers and teaching institutions and to sensitize directors, undergraduate and graduate students in order to produce knowledge about medication safety that can guide future improvements.

Our study suggests that the organization, distribution and packaging of the medications in the nursing station are system factors that may contribute to medication errors and related patient harms. For example, selection errors can occur as a consequence of the lack of organization in the cabinets and drawers or similar packages of different medications being distributed at the same location. Medications can also lose their effectiveness because of inadequate packaging and/or inappropriate storage.

The findings of workarounds, which are a frequent issue in health care, are concerning. Frequently, workarounds are the result of deficiencies in system or work design(23). Unfortunately, workarounds do not solve underlying problems ${ }^{(23)}$ like inadequate pharmacy services, and can even contribute to error ${ }^{(24)}$. Even with limited resources, nurses, administrators and other health professionals can use our research findings to explore potential improvements and decrease the pressure to use workarounds.

Our research design is replicable in several healthcare contexts and can involve health care professionals and students in detecting safety issues and generating evidence-based solutions that fit the resources and expertise of local environments. In our experience, the use of photographic methods enabled participants and researchers to collaboratively evaluate the organization, storage and distribution of medications and also raised the awareness and self-examination of students, faculty, nurses and managers in relation to the real, day-to-day context for working with medications in the study unit. Using a restorative approach to digital photography, photo elicitation and photo narration, we have identified several medication safety concerns, and also noted some better practices that could be reinforced to strengthen medication safety for professionals and patients.

\section{Conclusion}

The quality of nursing care reflects the quality and safety of patient care, and photographic research methods can help us manage risks in working with medication more thoughtfully. Using research to reduce risks for patients may help us shorten hospital stays, decrease the incidence of temporary or permanent inabilities, and even prevent some unnecessary deaths. With these ultimate goals in mind, we will continue our restorative research and work together with health care communities to create safe places, safer systems, and the safest possible patient care.

\section{References}

1. Institute of Medicine of the National Academies. The Chasm in Quality: Select the Indicators from Recent Reports. Institute of Medicine [internet]. 2006 [acesso: 24 mai 2008]. Disponível em: http://www.iom.edu/?id=14991

2. Joint Commission for Patient Safety. World Alliance for Patient Safety [internet]. 2008 [acesso: 30 jul. 2009] Disponível em: http://www.ccforpatientsafety.org/30730/

3. Anvisa. Anvisa promove debate sobre segurança do paciente no Brasil. Ministério da Saúde. [internet]. 2007 [acesso: 15 mai. 2008]. Disponível em: http://www.anvisa.gov.br/DIVULGA/ noticias/2007/171007.htm

4. Joint Commission for Patient Safety. Nine Patient Safety Solutions [internet]. 2008 [acesso: 15 jun 2008]. Disponível em: http://www.ccforpatientsafety.org/30723/

5. Joint Commission for Patient Safety. High 5s Project [internet]. 2008 [acesso: 15 jun 2008]. Disponível em: http://www. ccforpatientsafety.org/30753/
6. Department of Health. About Patient Safety [internet]. 2004 [acesso: 20 jun 2008]. Disponível em: http://www.dh.gov.uk/ en/Publichealth/Patientsafety/Patientsafetygeneralinformation/ DH_4066328

7. World Health Organization. 10 facts on patient safety [internet]. 2008 [acesso: 20 jun 2008]. Disponível em: http:// www.who.int/features/factfiles/patient_safety/en/index.html

8. Radünz V. Cuidando e se cuidando: fortalecendo o self do cliente oncológico e o self da enfermeira. 2a ed. Goiânia: AB; 1999.

9. Conselho Regional de Enfermagem de Santa Catarina. Código de Ética dos Profissionais de Enfermagem [internet]. 2007 [acesso: 05 jun 2008]. Disponível em: http://www.coren-sc. org.br/Empresa2/Cepreform.html

10. Constatinou E, Romaniuk D. Client Safety. In: Potter P, Perry A, Ross-Kerr, Wood M. Canadian Fundamentals of Nursing. Toronto: Elsevier; 2004. 
11. Organização Mundial da Saúde. 26a Conferência Sanitária Pan-americana 54a Sessão do Comitê Regional - Qualidade da Assistência: Segurança do Paciente. Organização Pan-Americana da Saúde [internet]. 2002 [acesso: 23 mai 2008] Disponível em: http://www.ops-oms.org/portuguese/gov/csp/csp26-26-p.pdf 12. Morse JM, Richards L. Read me first for a user's guide to qualitative methods. California: Sage Publications; 2002. 262 p. 13. Minayo MCS. Pesquisa Social: teoria, método e criatividade. Petrópolis: Vozes; 2002.

14. Society for Ecological Restoration International Science \& Policy Working Group. The SER International Primer on Ecological Restoration. 2004. [acesso: 21 oct 2005]. Disponível em: http:// www.ser.org

15. Marck PB. (Principal Investigator). Using restoration science to develop a digital photography assessment tool (DPAT). L Keehan, W Morgan Eckley, R Verluys (CIs) Funding: EFF Support for the Advancement of Scholarship Small Faculties Research Grant \# A021904; University of Alberta Establishment Grant (2005 - 2008). [online]. 2005 [acesso: 03 mai 2008]. Disponível em: http://researchandrestoration.ualberta.ca/research.php 16. Marck PB, Kwan JA, Preville B, Reynes M, Morgan-Eckley $W$, Versluys $R$, et al. Building Safer Systems by ecological design: Using restoration science to develop a medication safety intervention. Qual Saf Health Care. 2006;15:92-97.
17. Marck PB, Higgs ES, Vieira ER, Hagedorn K. Through the eyes of practitioners: Adapting visual research methods from ecological restoration to integrate the ethics, science, and practice of safety in health care. [internet] Proceedings; 25-27 Jun 2007; France. Strasbourg: Health Care Systems Ergonomics \& Patient Safety International Conference. p. 1 - 8. [accesso: 21 ago 2009]. Disponível em: http://www.nursing.ualberta. ca/SaferSystems/Publications_files/HEPS2008_Marck\%20 etal_11April2008.pdf .

18. Marck PB. Discourse. Field notes from research and restoration in the backcountry of modern health care. Can J Nurs Res. 2006;38(2):11-23.

19. Higgs ES. Nature by design. People, natural process, and ecological restoration. Massachusetts: MIT Press; 2003.

20. Marck PB. Ethics in hard places: The ecology of safer systems in modern health care. Health Ethics Today [internet]. 2004 [acceso: 21 ago 2009];14(1):2-5. Disponível em: http:// www.ualberta.ca/BIOETHICS/HET\%20pdfs/Vol.14,\%20No\%20 1\%20-\%202004.pdf

21. Koppel R. Workarounds to Barcode Medication Administration Systems: Their Occurrences, Causes, and Threats to Patient Safety. J Am Med Inform Assoc. 2008;15:408-23.

22. Marck PB, Cassiani SHB. Teorizando sobre sistemas: uma tarefa ecologica para as pesquisas na area de seguranca do paciente. Rev. Latino-Am. Enfermagem. 2005;13(5):750-3. Inglês.

23. Vogelsmeier A. Technology Implementation and Workarounds in the Nursing Home. J Am Med Inform Assoc. 2008;15:114-9.

24. Amalberti R. Violations and migrations in health care: a framework for understanding and management. Qual Saf Health Care. 2006;15(S1):i66-i71. 